Please do not remove this page

RMIT

UNIVERSITY

\title{
A fundamental model of quasi-static wheelchair biomechanics
}

Leary, Martin; Gruijters, Jan; Mazur, Maciej; Subic, Aleksandar; Burton, Mike; Fuss, Franz

https://researchrepository.rmit.edu.au/esploro/outputs/9921858930401341/filesAndLinks?institution=61RMIT_INST\&index=null

Leary, M., Gruijters, J., Mazur, M., Subic, A., Burton, M., \& Fuss, F. (2012). A fundamental model of quasi-static wheelchair biomechanics. Medical Engineering and Physics, 34(9), 1278-1286.

https://doi.org/10.1016/j.medengphy.2011.12.018

Document Version: Accepted Manuscript

Published Version: https://doi.org/10.1016/j.medengphy.2011.12.018

Repository homepage: https://researchrepository.rmit.edu.au

(C) 2012 Published by Elsevier Ltd on behalf of IPEM

Downloaded On 2023/04/26 21:24:52 +1000

Please do not remove this page 
Thank you for downloading this document from the RMIT Research Repository.

The RMIT Research Repository is an open access database showcasing the research outputs of RMIT University researchers.

RMIT Research Repository: http://researchbank.rmit.edu.au/

\section{Citation:}

Leary, M, Gruijters, J, Mazur, M, Subic, A, Burton, M and Fuss, F 2012, 'A fundamental model of quasi-static wheelchair biomechanics', Medical Engineering and Physics, vol. 34, no. 9 , pp. $1278-1286$.

See this record in the RMIT Research Repository at:

http://researchbank.rmit.edu.au/view/rmit:17913

Version: Accepted Manuscript

Copyright Statement: (c) 2012 Published by Elsevier Ltd on behalf of IPEM

Link to Published Version:

http://dx.doi.org/10.1016/j.medengphy.2011.12.018 


\title{
A Fundamental Model of Quasi-Static Wheelchair Biomechanics
}

\author{
M. Leary, J. Gruitjers, M. Mazur, A. Subic, M. Burton, F.K. Fuss. \\ School of Aerospace, Mechanical and Manufacturing Engineering. \\ RMIT University, Melbourne, Australia. \\ e: martin.leary@rmit.edu.au \\ p: (+61) 428955563
}

\begin{abstract}
The performance of a wheelchair system is a function of user anatomy, including arm segment lengths and muscle parameters, and wheelchair geometry, in particular, seat position relative to the wheel hub. To quantify performance, researchers have proposed a number of predictive models. In particular, the model proposed by Richter is extremely useful for providing initial analysis as it is simple to apply and provides insight into the peak and transient joint torques required to achieve a given angular velocity. The work presented in this paper identifies and corrects a critical error; specifically that the Richter model incorrectly predicts that shoulder torque is due to an anteflexing muscle moment. This identified error was confirmed analytically, graphically and numerically. The authors have developed a corrected, fundamental model which identifies that the shoulder anteflexes only in the first half of the push phase and retroflexes in the second half. The fundamental model has been extended by the authors to obtain novel data on joint and net power as a function of push progress. These outcomes indicate that shoulder power is positive in the first half of the push phase (concentrically contracting anteflexors) and negative in the second half (eccentrically contracting retroflexors). As the eccentric contraction introduces adverse negative power, these considerations are essential when optimising wheelchair design in terms of the user's musculoskeletal system. The proposed fundamental model was applied to assess the effect of vertical seat position on joint torques and power. Increasing the seat height increases the peak positive (concentric) shoulder and elbow torques while reducing the associated (eccentric) peak negative torque. Furthermore, the transition from positive to negative shoulder torque (as well as from positive to negative power) occurs later in the push phase with increasing seat height. These outcomes will aid in the optimisation of manual wheelchair propulsion biomechanics by minimising adverse negative muscle power, and allow joint torques to be manipulated as required to minimise injury or aid in rehabilitation.
\end{abstract}

Keywords: Wheelchair propulsion biomechanics, optimisation, human-machine interface, biomechanical modelling 


\section{Nomenclature}

$\theta \quad$ angular position of a limb segment

$\theta_{c} \quad$ contact angle

$\theta_{r} \quad$ release angle

$\theta_{e} \quad$ elbow angle

$\theta_{s} \quad$ shoulder angle

$\theta_{e i} \quad$ initial elbow angle

$\theta_{s i} \quad$ initial shoulder angle

$\theta_{w} \quad$ wheel angle

$\theta_{i} \quad$ intermediate angle (between shoulder reference line and $a$ )

$\theta_{h s} \quad$ angle of the shoulder to the wheel hub

$\theta_{f} \quad$ pushrim force vector angle

$\omega$ angular velocity of limb segment

$\omega_{w} \quad$ angular velocity of wheel

a distance from hand to shoulder

$L_{u a} \quad$ upper-arm length

$L_{f a} \quad$ forearm length

$R_{H R} \quad$ pushrim radius

$L_{H S} \quad$ distance from wheel hub to shoulder

$P P \quad$ push progress (\%)

$F \quad$ pushrim force magnitude

$F_{r} \quad$ radial pushrim force

$F_{t} \quad$ tangential pushrim force

$F_{m} \quad$ muscle force

$T_{s} \quad$ quasi-static torque applied to the shoulder

$T_{e} \quad$ quasi-static torque applied to the elbow

$v \quad$ muscle fibre velocity (shortening or stretching)

\section{Introduction}

The manual wheelchair is a core enabling technology which provides opportunities for rehabilitation, mobility and athletic competition. Distinct wheelchair types have been developed in response to these specific use-scenarios. For example: rehabilitation wheelchairs are intended for short-term use, and provide a reasonable level of comfort and efficiency while accommodating the anatomy of a range of potential users; mobility wheelchairs are used by a specific individual, with the objective of maximising comfort and efficiency while meeting the constraints of everyday use; competition wheelchairs are designed to maximise athletic performance in specific sports such as rugby, tennis, track racing, or basketball.

For a given set of user attributes, the performance of a wheelchair and user may be defined by various parameters, including: energy efficiency, maximum speed, joint torques, joint power and net power. The consequences of non-optimal design are an increased potential for injury, 
or compromised physical performance. Design optimisation is achieved by either experimental or theoretical methods, or a combined approach.

The interaction between user and wheelchair is highly complex. Much of this complexity is due to the individual biomechanical attributes of a specific user. For example, experimental observation by the authors identified various propulsion patterns for different users, and variation in use patterns for individual users (Figure 1). Observational studies indicate significant variability in the biomechanics of different users under differing scenarios. Influential factors include [1-6]: whether the activity is athletic or mobility, and the specific user disability. Furthermore, propulsion patterns may be time dependant, for example, an athlete may temporarily employ a single handed propulsion technique to allow muscle recovery of the resting arm.
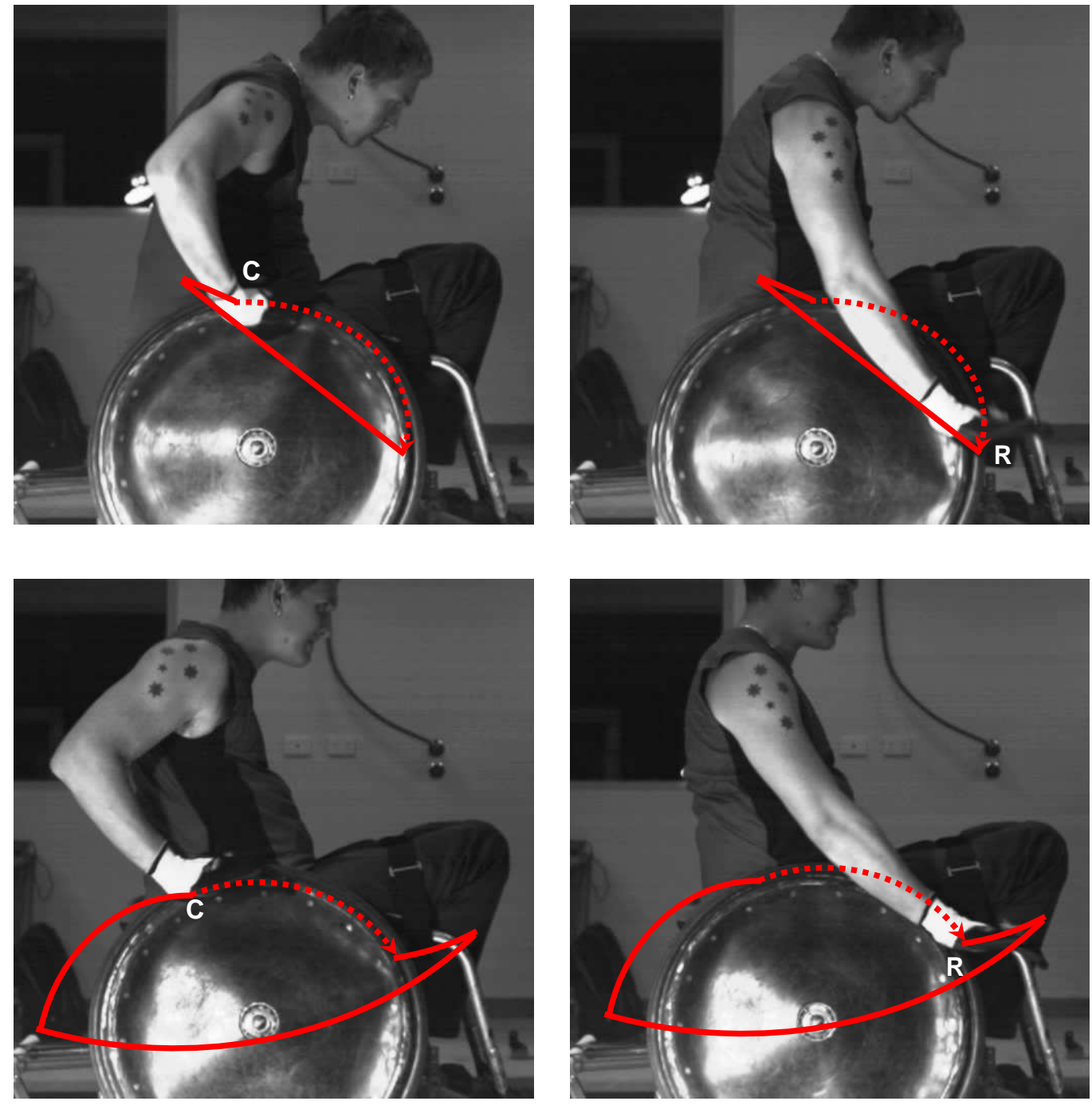

Figure 1. Sample observations of push pattern and variation with time (rugby athlete on ergometer). Dashed line indicates contact with wheel.

Nomenclature: contact point $(C)$, release point $(R)$.

Left: Contact angle. Right: Release angle.

Upper: Push pattern of rested user. Lower: Push pattern of fatigued user. 
These complexities may be accommodated by physical testing of a user in a specific scenario. Experimental testing enables performance attributes to be accurately acquired for a specific scenario, for example $[4,7,8,9,10,11,13,14,15,16]$. Despite these advantages, experimental studies are subject to technical limitations in data acquisition, and are relatively time consuming and expensive to implement. The outcomes of experimental analysis are fundamentally limited in providing insight into the performance for alternate scenarios and do not provide a platform for the optimisation of a particular scenario.

Theoretical models provide a low cost method of simulating a physical scenario. This approach enables the rapid analysis of disparate scenarios and provides an important opportunity for the optimisation of wheelchair systems. Theoretical analysis is typically based on a parametric model of the wheelchair and user biomechanics. Once the model is established, iterative analysis can be automated to assess an extensive range of feasible parameters. This provides a significant opportunity to explore alternate design scenarios and to optimise performance for a particular use-scenario.

Unlike experimental analysis, theoretical modelling does not directly accommodate the complexities of user biomechanics. Modelling error occurs if the theoretical model does not represent the associated biomechanics with sufficient accuracy. In addition, the available data on user attributes are limited, and various assumptions are made to overcome this limitation. A series of theoretical models have been proposed in the literature, all of which result in some compromise between complexity and accuracy.

Inverse kinematic and dynamic models have been developed in other biomechanical domains, such as running and reaching, for example $[17,18,19]$. These models provide insight into joint torques and associated energy transfer. Early work in the field of wheelchair biomechanics was completed by Brubaker, who modelled the wheelchair and user as two centres of mass; one for the upper body and one for the lower extremities and the wheelchair [20]. This work proved that performance is highly dependent on the attributes of a specific user, and that wheelchair parameters should be tailored to match these attributes. Energy balance and power flow models have been applied to assess upper extremity biomechanics during wheelchair propulsion [22]. To provide further insight into muscle forces and joint torques during wheelchair propulsion, biomechanical models have been developed, including: a finite element model developed by van der Helm [21]; a model of glenohumeral joint kinematics by Cooper et al. [23, 24]; generalised limb segment models proposed by Dumas et al. [25, 26]; and a generalised model of the upper limb developed by Pennestrì et al. [28]. Furthermore, commercially available multibody computational models have been applied with the objective of realistically accommodating the complexity of the shoulder, for example [27]. These models provide high resolution of three dimensional biomechanics, including dynamic effects. However, it is difficult to comprehensively acquire the biomechanical data required for these models; consequently their applicability may be limited in practice.

Richter proposed a two dimensional model of biomechanics for the manual wheelchair propulsion cycle [29]. This model represents the user and wheelchair as a quasi-static, four 
bar linkage with one degree of freedom (Figure 2). The model allows parametric manipulation of user limb lengths, as well as horizontal and vertical seat position. This representation is advantageous as it is compatible with the available data on handrim force profiles, and provides insight into the peak and transient shoulder and elbow torques, which are important for improving athletic performance and injury prevention. Despite the advantages of this model, the formulation proposed by Richter is incorrect, resulting in erroneous predictions of shoulder torque. This work identifies and corrects this critical error and proposes a corrected fundamental model. The capability of this fundamental model is extended to quantify joint and net power as a function of push progress.

\section{Method}

A quasi-static model of wheelchair propulsion which represents the wheelchair and user as a planar four-bar linkage with one degree of freedom was proposed by Richter [29]. This model (Figure 2) is extremely useful for providing insight into wheelchair biomechanics.

This work identifies and corrects a critical error in the work proposed by Richter [29]. A direct mathematical proof is developed in this work to provide a corrected, fundamental model of quasi-static wheelchair biomechanics; this model is confirmed by three independent methods (Section 2). This fundamental model is then extended to obtain previously unavailable data on joint and net power as a function of push progress (Section 3). 


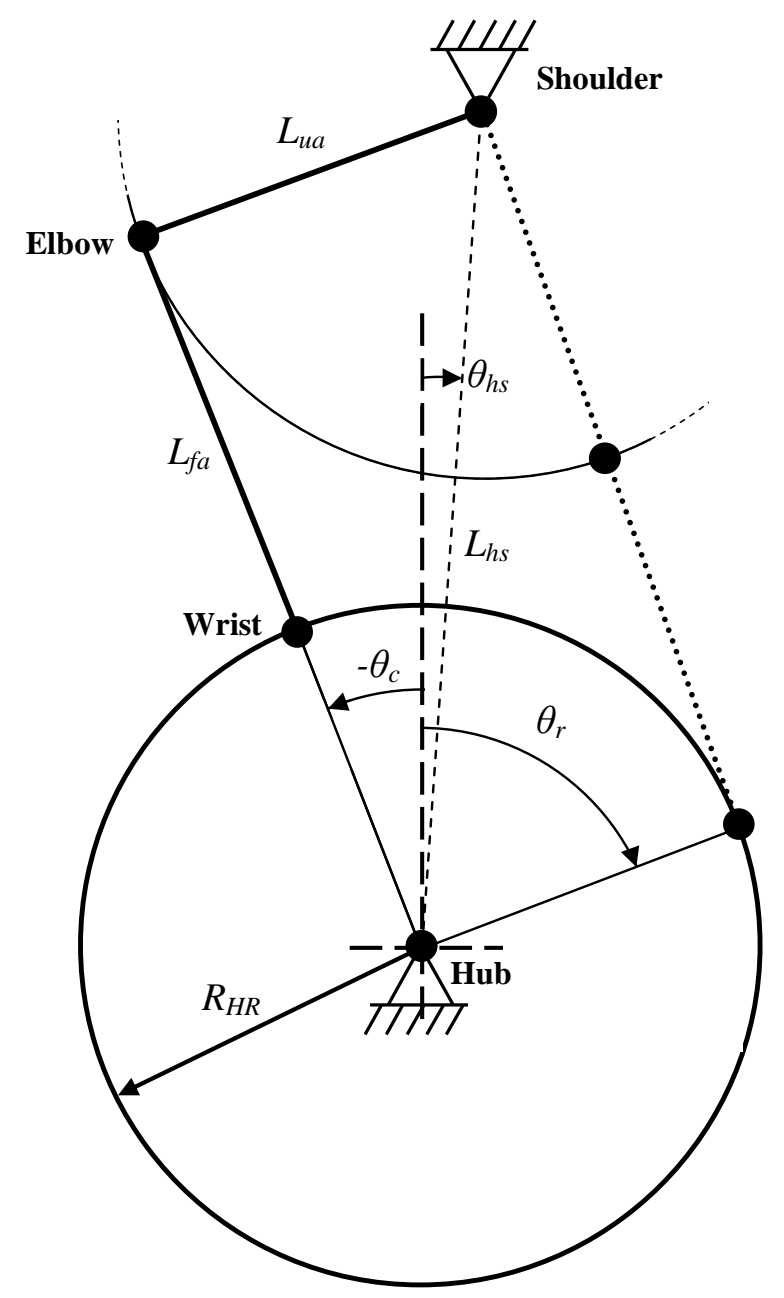

Figure 2: Quasi-static wheelchair and arm model based on [29].

Arm shown at contact angle (solid line) and release angle (dotted line). Angles shown in positive direction except as indicated with a negative sign. 


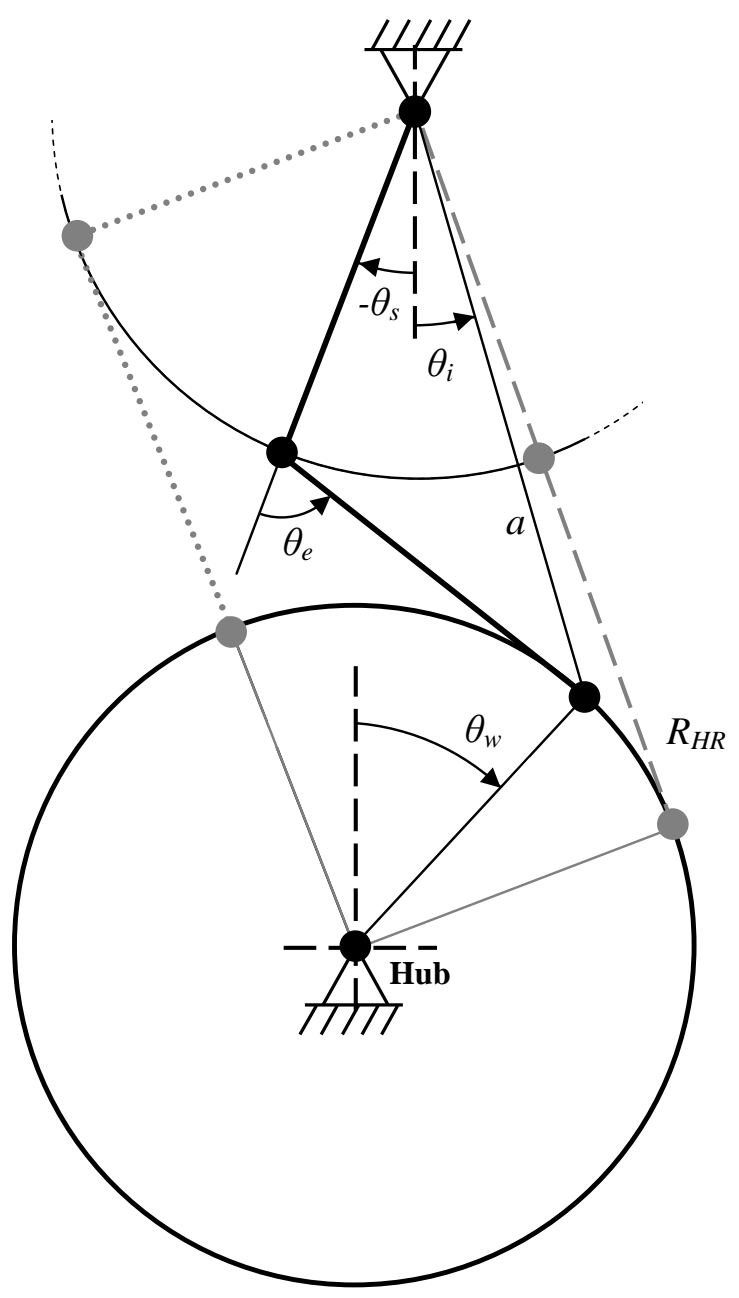

Figure 3: Quasi-static wheelchair and arm model indicating sense of shoulder and elbow torques and wheel angle. Dashed line indicates the arm in the fully extended position (push progress $=100 \%$ ), dotted line indicates arm in initial position (push progress $=0 \%$ ). Angles shown in positive direction except as indicated with a negative sign. 


\subsection{Analytical solution}

The following section develops an analytical derivation of the elbow and shoulder torques based on the following assumptions, as defined by Richter [29]:

- The arm and wheel share a common plane perpendicular to the hub axle. This useful approximation is more representative of higher seat positions as shoulder abduction is low.

- The contact angle, $\theta_{c}$, is the wheel angle at which the hand first contacts the handrim. The forearm is assumed to be perpendicular to the handrim at the contact angle.

- The release angle, $\theta_{r}$, is the angle of the wheel when the hand releases the handrim. The release angle is defined as the wheel angle when the forearm and upper arm are coaxial.

- The hand is in continuous contact with the handrim between the contact and release angle.

- The radial and tangential forces are defined as a function of push progress.

- The dynamic effects of limb mass and wheel inertia are not accommodated. This assumption appears valid as dynamic effects are negligibly small in comparison with direct forces [30].

- Shoulder position remains constant through the push cycle. This assumption may be valid for some users; however, applicability is compromised if the shoulder position moves during propulsion, for example (Figure 1). The magnitude of this error is not explicitly assessed in this work, although this effect may be of relevance [31].

- Progress of the wheel from contact to release angle is defined in terms of the push progress and is reported independently of the associated push time.

- Angular wheel velocity is assumed constant (Section 4).

The following, direct mathematical proof is presented in full to allow the reader to confirm the correctness of the proposed fundamental model.

\subsubsection{Model angles}

Contact and release angles are calculated from the system geometry based on the assumptions described in Section 2.1. These angles are defined as positive in the clockwise direction from the vertical axis at the wheel hub (Figure 2). At the contact angle, $\theta_{c}$, the forearm is perpendicular to the handrim and therefore aligned with the wheel hub. From the law of cosines (Figure 2):

$$
L_{u a}^{2}=L_{h s}^{2}+\left(L_{f a}+R_{H R}\right)^{2}-2 L_{h s}\left(L_{f a}+R_{H R}\right) \cos \left(\theta_{h s}-\theta_{c}\right)
$$

The contact angle is therefore:

$$
\theta_{c}=\theta_{h s}-\cos ^{-1}\left(\frac{L_{h s}^{2}+\left(L_{f a}+R_{H R}\right)^{2}-L_{u a}^{2}}{2 L_{h s}\left(L_{f a}+R_{H R}\right)}\right)
$$

At the release angle, $\theta_{r}$, the forearm and upper arm are collinear, i.e. the elbow angle, $\theta_{e}=0$, therefore (Figure 2): 


$$
\begin{aligned}
& \left(L_{f a}+L_{u a}\right)^{2}=L_{h s}^{2}+R_{H R}^{2}-2 L_{h s} R_{H R} \cos \left(\theta_{r}-\theta_{h s}\right) \\
& \theta_{r}=\theta_{h s}+\cos ^{-1}\left(\frac{L_{h s}^{2}+R_{H R}^{2}-\left(L_{f a}+L_{u a}\right)^{2}}{2 L_{h s} R_{H R}}\right)
\end{aligned}
$$

These contact and release angles match those defined by Richter [29].

The wheel angle, $\theta_{w}$, can be used to indicate the push progress, $P P$, as a fraction of the total push cycle completed:

$$
P P=\left(\theta_{w}-\theta_{C}\right) /\left(\theta_{r}-\theta_{C}\right) \times 100 \%
$$

In order to calculate the shoulder and elbow angles, the distance between the wrist and shoulder, $a$, is calculated as the hypotenuse of a right angled triangle whose shorter sides are formed by the horizontal and vertical components of the length from hub to shoulder $L_{h s}$ (Figure 2) and the pushrim radius $R_{H R}$ (Figure 3).

$$
a=\sqrt{\left(R_{H R} \sin \left(\theta_{w}\right)-L_{h s} \sin \left(\theta_{h s}\right)\right)^{2}+\left(L_{h s} \cos \left(\theta_{h s}\right)-R_{H R} \cos \left(\theta_{w}\right)\right)^{2}}
$$

The shoulder angle, $\theta_{s}$, is calculated as follows:

$$
\begin{aligned}
& L_{f a}^{2}=L_{u a}^{2}+a^{2}-2 L_{u a} a \cos \left(\theta_{i}-\theta_{s}\right) \\
& \theta_{s}=\theta_{i}-\cos ^{-1}\left(\frac{L_{u a}^{2}+a^{2}-L_{f a}^{2}}{2 L_{u a} a}\right)
\end{aligned}
$$

Where $\theta_{i}$ is the intermediate angle, defined from shoulder to wrist:

$$
\theta_{i}=-\tan ^{-1}\left(\frac{L_{h s} \sin \left(\theta_{h s}\right)-R_{H R} \sin \left(\theta_{w}\right)}{L_{h s} \cos \left(\theta_{h s}\right)-R_{H R} \cos \left(\theta_{w}\right)}\right)
$$

The elbow angle, $\theta_{e}$, is calculated similarly:

$$
\begin{aligned}
& a^{2}=L_{u a}^{2}+L_{f a}^{2}-2 L_{u a} L_{f a} \cos \left(\pi-\theta_{e}\right)=L_{u a}^{2}+L_{f a}^{2}+2 L_{u a} L_{f a} \cos \left(\theta_{e}\right) \\
& \theta_{e}=\pi-\cos ^{-1}\left(\frac{L_{u a}^{2}+L_{f a}^{2}-a^{2}}{2 L_{u a} L_{f a}}\right)=\cos ^{-1}\left(\frac{a^{2}-L_{u a}^{2}-L_{f a}^{2}}{2 L_{u a} L_{f a}}\right)
\end{aligned}
$$

The initial shoulder, $\theta_{s i}$, and initial elbow, $\theta_{e i}$, angles are calculated by solving for $\theta_{w}=\theta_{c}$ and $\theta_{w}=\theta_{r}$, respectively. 


\subsubsection{Shoulder and elbow torques}

For a defined user push force profile, the shoulder and elbow torques are calculated from the associated force vector and the position of the limb segments. The angle of the force vector, $\theta_{f}$, is defined with respect to the handrim; the force angle is defined as zero for an input force tangential to the handrim where clockwise rotation is positive.

$$
\theta_{f}=\tan ^{-1}\left(\frac{\left|F_{r}\right|}{\left|F_{t}\right|}\right)=\cos ^{-1}\left(\frac{\left|F_{t}\right|}{|F|}\right)=\sin ^{-1}\left(\frac{\left|F_{r}\right|}{|F|}\right)
$$

The analytical calculation of the shoulder and elbow torques is made by inspection of free body diagrams of the upper arm and forearm. By applying equations of equilibrium, the quasi-static shoulder torque, $T_{s}$, and elbow torque, $T_{e}$, are defined as a function of the force vector and wheel angle. By inspection of the force vector components, limb angles, and wheel angles the elbow torque is:

$$
\begin{aligned}
& \sum M_{e}=T_{e}-F L_{f a} \cos \left(\theta_{f}+\theta_{w}\right) \cos \left(\theta_{s}+\theta_{e}\right)+F L_{f a} \sin \left(\theta_{f}+\theta_{w}\right) \sin \left(\theta_{s}+\theta_{e}\right)=0 \\
& \therefore T_{e}=F L_{f a}\left[\cos \left(\theta_{f}+\theta_{w}\right) \cos \left(\theta_{s}+\theta_{e}\right)-\sin \left(\theta_{f}+\theta_{w}\right) \sin \left(\theta_{s}+\theta_{e}\right)\right\rfloor \\
& T_{e}=F L_{f a} \cos \left(\theta_{s}+\theta_{e}+\theta_{f}+\theta_{w}\right)
\end{aligned}
$$

Shoulder torque is calculated as follows:

$$
\begin{aligned}
& \sum M_{s}=T_{s}-T_{e}-L_{u a} F \cos \left(\theta_{s}\right) \cos \left(\theta_{f}+\theta_{w}\right)-L_{u a} F \sin \left(\theta_{s}\right) \sin \left(\theta_{f}+\theta_{w}\right)=0 \\
& \therefore T_{s}=T_{e}+F L_{u a}\left\lfloor\cos \left(\theta_{s}\right) \cos \left(\theta_{f}+\theta_{w}\right)+\sin \left(\theta_{s}\right) \sin \left(\theta_{f}+\theta_{w}\right)\right\rfloor \\
& T_{s}=T_{e}+F L_{u a} \cos \left(\theta_{s}+\theta_{f}+\theta_{w}\right)
\end{aligned}
$$

The elbow torque derived in this work (Equation 14) matches that derived by Richter [29], however the shoulder torque does not (Equation 15). The moments about any fixed point should sum to zero at all times if the constituent equations are correctly derived. Unlike the model proposed by Richter, the sum of moments about the shoulder joint correctly sum to zero (Equation 16) for the proposed fundamental model, as required for quasi-static equilibrium.

$$
\begin{aligned}
& \sum M_{s}=T_{s}-F \cos \left(\theta_{F}+\theta_{w}\right)\left(L_{f a} \cos \left(\theta_{s}+\theta_{e}\right)+L_{u a} \cos \left(\theta_{s}\right)\right) \\
& +F \sin \left(\theta_{F}+\theta_{w}\right)\left(L_{f a} \sin \left(\theta_{s}+\theta_{e}\right)+L_{u a} \sin \left(\theta_{s}\right)\right)=0
\end{aligned}
$$

As a complete mathematical proof is not available, it is not possible to identify the explicit error in the work provided by Richter [29]. However, the correctness of the fundamental model proposed in this work is corroborated by independent graphical and numerical methods. 


\subsection{Graphical solution}

The analytical results reveal a discrepancy between the shoulder torque derived in this work and that presented by Richter [29] (Figure 5). In the second half of the push progress, the shoulder torque reported by Richter is positive, i.e. produced by an anteflexing muscle moment (e.g. pectoralis major, anterior part of deltoid) whereas the result of Equation 15 is negative, i.e. produced by a retroflexing muscle moment (e.g. latissimus dorsi, posterior part of deltoid). This contradiction can be clarified by graphical analysis. The line of action of the resultant force at a push progress of approximately $72 \%$ passes in front of the shoulder joint and is therefore due to a retroflexing muscle moment (Figure 6). This outcome corroborates the analytical results proposed in this work.

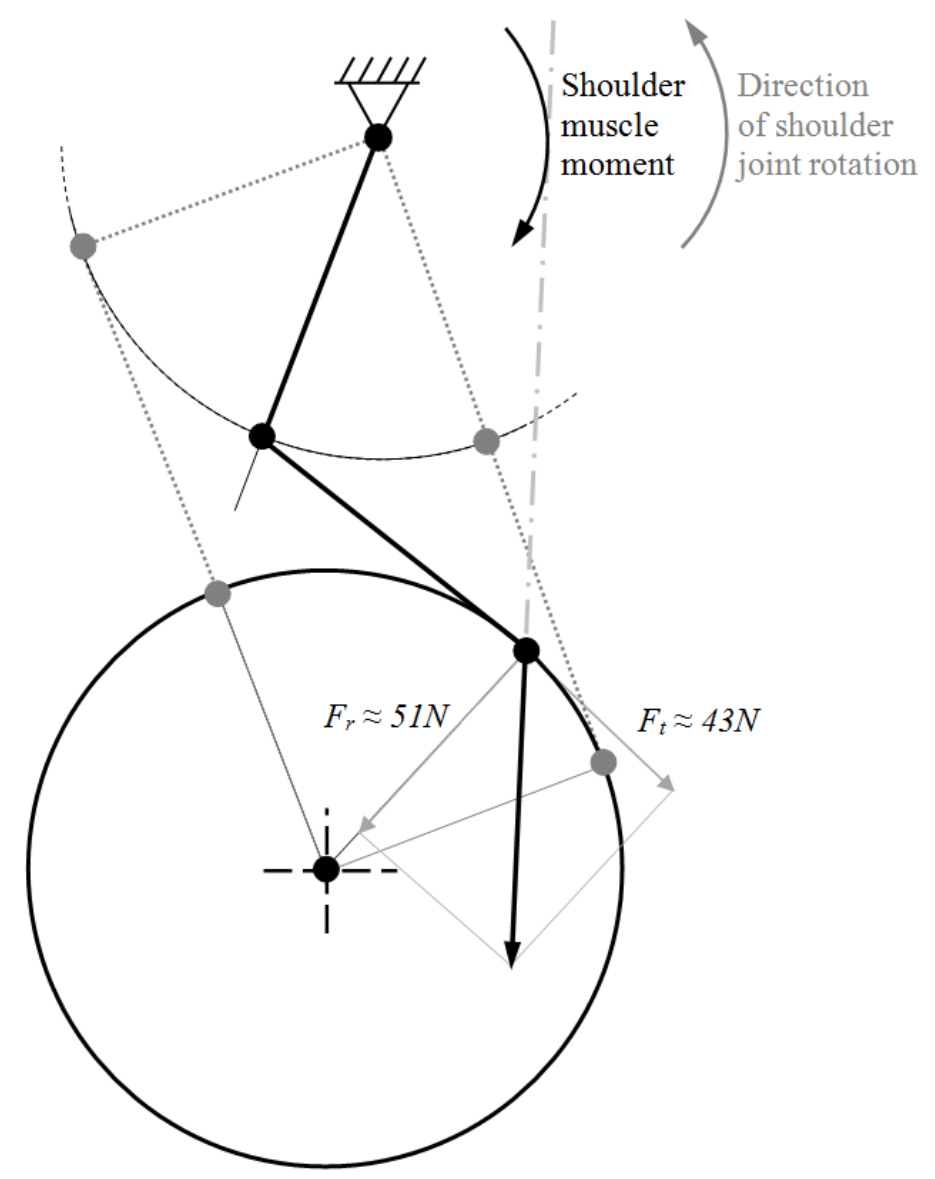

Figure 6: Graphical solution at a push progress $(P P)$ of approximately $72 \%, F_{t}$ and $F_{r}$ from Figure 4. The resultant force passes in front of the shoulder joint and is therefore due to a retroflexing muscle moment at the shoulder joint. Nomenclature: $F_{t}=$ tangential force, $F_{r}=$ radial force, $F=$ resultant force. 


\subsection{Numeric solution}

Numeric analysis provides an alternative method for estimating the shoulder and elbow torques, thereby providing an independent method for validation of the accuracy of the proposed fundamental model. For this purpose a parametric model was developed using commercial simulation software [41]. The model consists of three rotational joints (Figure 7):

- shoulder joint allows in-plane rotation only

- elbow and wrist joints allow in-plane rotation and translate as required to maintain wrist contact with the wheel as it rotates

The push force vector is input at the wrist joint, and the shoulder and elbow torques required to achieve static equilibrium are calculated (Figure 7). The numeric solution matches the obtained analytic results (Eq. 11 and 12, Figure 5), thereby confirming that the proposed fundamental model correctly predicts the shoulder torque.
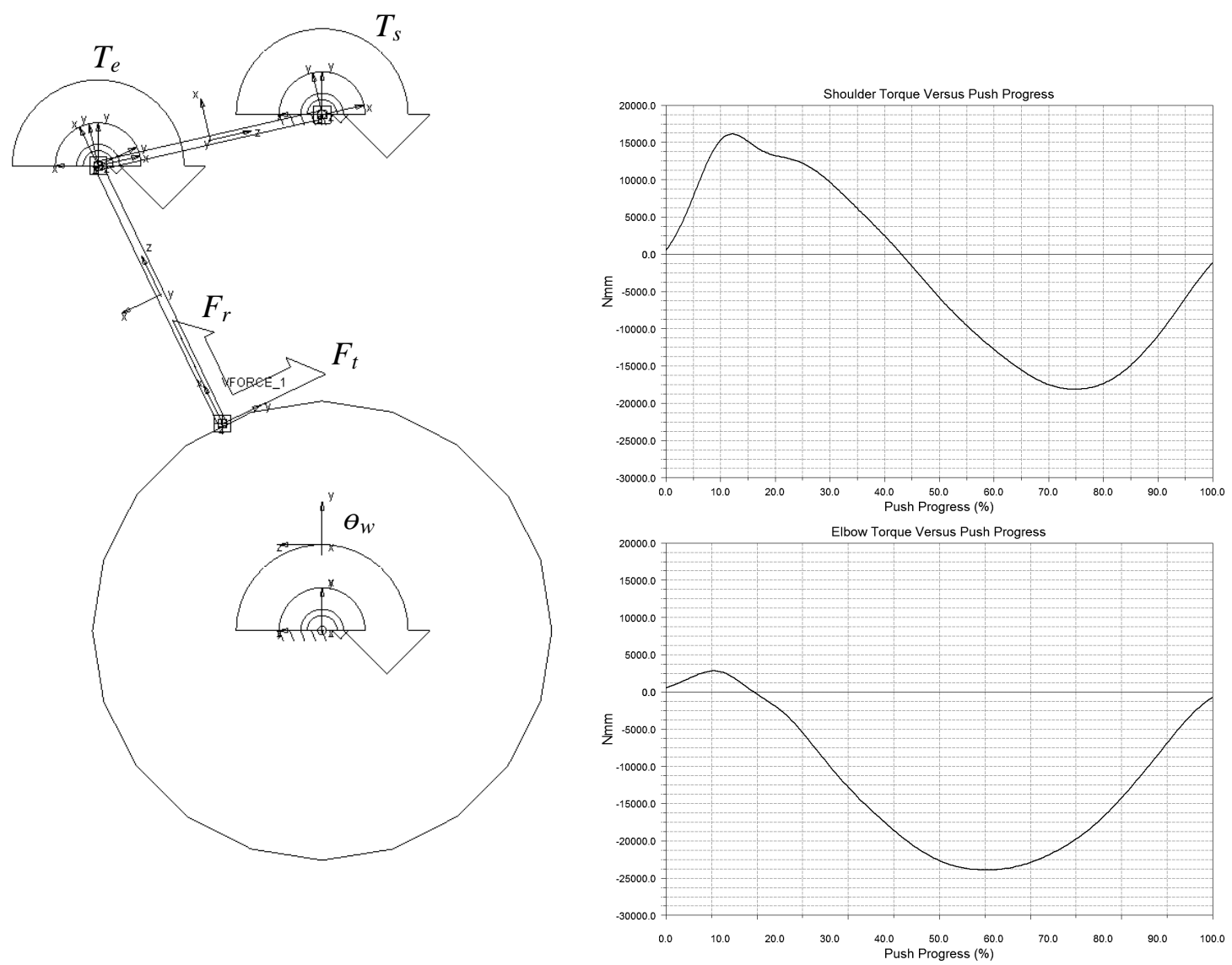

Figure 7. Left: Numeric model of wheelchair and user.

Right: Numeric simulation results confirming the results of the analytical model (Figure 5). Nomenclature: $T_{e}=$ elbow torque, $T_{s}=$ shoulder torque, $\theta_{w}=$ wheel angle, $F_{t}=$ tangential force, $F_{r}=$ radial force, $F=$ resultant force. Torque and rotation sense defined as for Figure 3. 


\subsection{Input data}

The model input data consists of limb lengths and the radial and tangential components of push force versus push progress. To assess the proposed torque equations, the user data referenced by Richter [29] was applied to the proposed model:

- $\quad$ Upper-arm length, $L_{u a}=26.7 \mathrm{~cm}$

- Forearm length (including half hand), $L_{f a}=33.3 \mathrm{~cm}$

- Handrim radius, $R_{H R}=26.7 \mathrm{~cm}$

- Constant length from shoulder to hub $L_{h s}=60 \mathrm{~cm}$

- Angle from hub to shoulder, $\theta_{h s}=0^{\circ}$

The model requires an estimate of the push force vector as a function of push progress. Empirical push force data are available in the literature, however, results may be difficult to compare due to differences in experimental method, and results differ significantly between studies. For example, the observed radial force may exceed the tangential force [29, 32], or the opposite may be true [30]. Athletes also show a larger tangential force component in comparison with everyday users [4]. It is imperative that the user input data match the intended users to maximise the applicability of the model outcomes. In this work, radial, $F_{r}$, and tangential, $F_{t}$, handrim forces are based on average measurements of five sampled wheelchair users who propelled their own wheelchairs on an dynamometer at $1.4 \mathrm{~m} / \mathrm{s}$, with a resistance equivalent to a $2 \%$ (1:50) grade (Figure 4) [29].

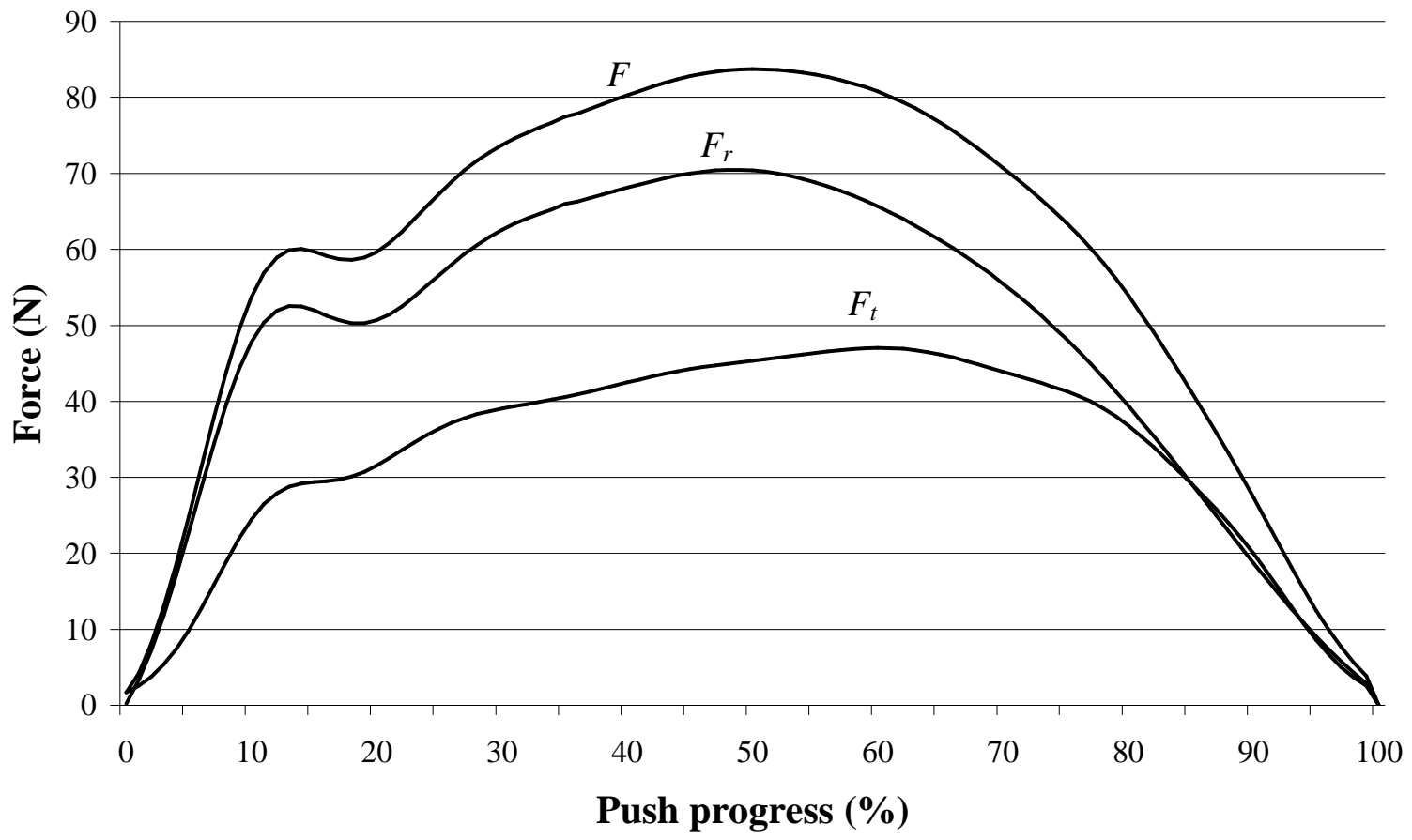

Figure 4. Digitised push force data based on [29] (Appendix A). $F=$ resultant force, $F_{t}=$ tangential force, $F_{r}=$ radial force . 


\section{Results}

The input data defined in Section 2.4 were applied to both the fundamental model developed in this work, and the results proposed by Richter (Figure 5, Table 1). Based on the obtained simulation results, the elbow torque calculated by Richter's equation matches that of Equation 14. However, the Richter model: does not correctly predict the shoulder torque profile; marginally overestimates peak positive shoulder torque and the associated push progress; and, differs significantly in the prediction of the minimum peak value.

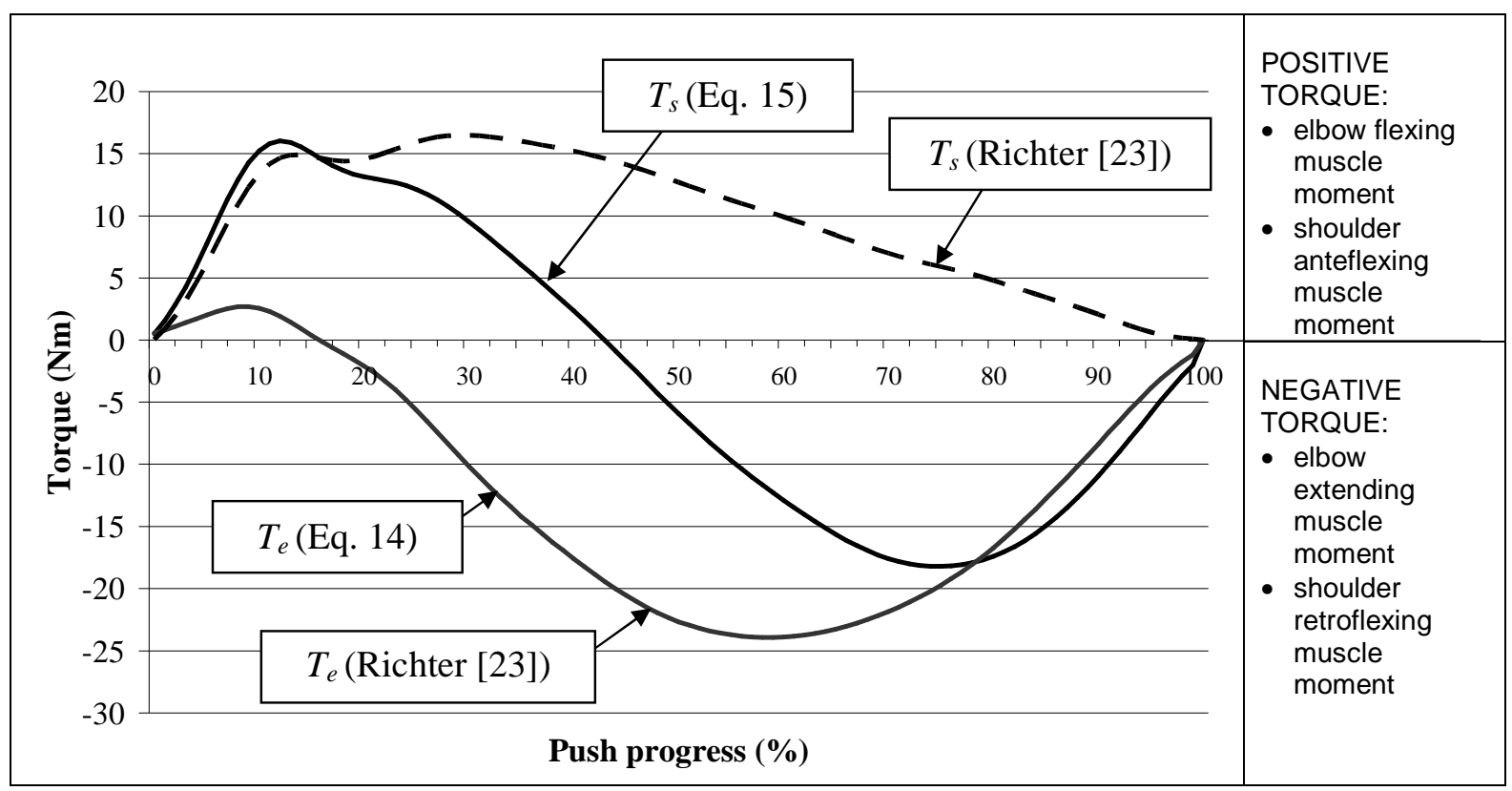

Figure 5. Elbow and shoulder torque.

Nomenclature: $T_{e}=$ elbow torque, $T_{s}=$ shoulder torque.

Table 1. Comparison of elbow and shoulder torques.

\begin{tabular}{|c|c|c|c|}
\hline & \multicolumn{2}{|c|}{ Torque $(\mathrm{Nm})$} \\
\hline & & Maximum & Minimum \\
\hline \multirow{2}{*}{ Shoulder } & Richter [29] & $\begin{array}{c}16.5 \\
P P=29.5 \%\end{array}$ & $\begin{array}{c}0 \\
P P=(0,100 \%)\end{array}$ \\
\hline & Eq. 15 & $\begin{array}{c}16 \\
P P=12 \%\end{array}$ & $\begin{array}{c}-18.2 \\
P P=75 \%\end{array}$ \\
\hline \multirow{2}{*}{ Elbow } & Richter [29] & $\begin{array}{c}2.7 \\
P P=8.5 \%\end{array}$ & $\begin{array}{c}-23.9 \\
P P=58.5 \%\end{array}$ \\
\hline & Eq. 14 & $\begin{array}{c}2.7 \\
P P=8.5 \%\end{array}$ & $\begin{array}{c}-23.9 \\
P P=58.5 \%\end{array}$ \\
\hline
\end{tabular}


The proposed fundamental model provides an exceptional opportunity to gain insight into the fundamental biomechanics of wheelchair and user in a manner that is compatible with readily available experimental data. In particular, the fundamental model allows parametric manipulation of user and wheelchair data to optimise for parameters of relevance, including injury prevention (minimisation of peak forces [1,3,12,30]) and athletic performance (maximisation of power output, or propulsion efficiency [12,37]).

Seat position is an important factor in regard to injury prevention and propulsion efficiency. Experimental studies indicate that when the wheel hub is moved forward relative to the shoulder joint, the push frequency decreases, as does the rate of change in total force $[1,3,40]$. When the vertical displacement of the shoulder relative to the hub is lowered, the total arc of wheel travel increases, as does push frequency $[1,3,39,40]$. However, a very low seat position may result in excessive shoulder abduction [3].

The proposed fundamental model has been applied to assess the effect of vertical seat position on elbow and shoulder torques. Shoulder and elbow torques have been assessed for the scenario of Section 3, with the shoulder position assessed within the range of $L_{H S} \pm 10 \mathrm{~cm}$ in $2.5 \mathrm{~cm}$ increments (Figure 10). According to these results, for both elbow and shoulder torque, increasing the seat height results in: an increase in the magnitude of the peak positive torque, and a decrease in the magnitude of the peak negative torque; with the change in positive torque being less than the change in the negative torque.

The outcomes of this work indicate that vertical seat position can be used to manipulate the relative magnitude of the positive and negative components of the peak torque observed by the shoulder and elbow (Figure 10). In terms of injury prevention, this outcome allows vertical seat position to be manipulated to avoid injury to a particular muscle group. For example, increasing vertical seat position will result in an increase in the peak anteflexing muscle moment (e.g. pectoralis major, anterior part of deltoid), and an associated reduction in the peak retroflexing muscle moment (e.g. latissimus dorsi, posterior part of deltoid). 

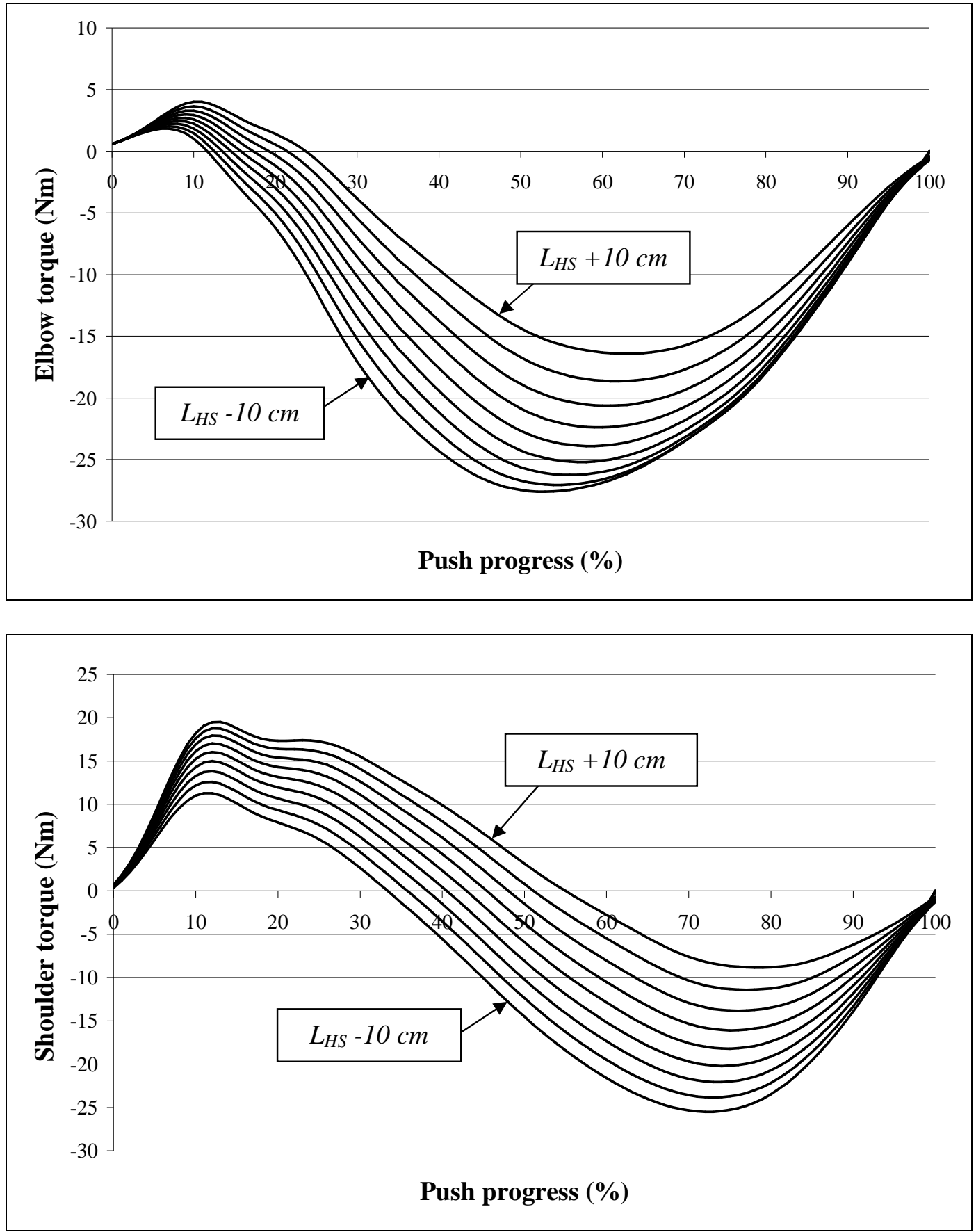

Figure 10. Variation of torque versus seat position. Upper: Elbow. Lower: Shoulder. 


\section{Extension of the fundamental model to joint power}

If muscle moment and joint rotation have the same sense (i.e. direction of rotation), the muscle contracts concentrically and adds power to the system (Figure 8). In the case of opposing muscle moment and joint rotation, the muscle contracts eccentrically which takes power from the system.

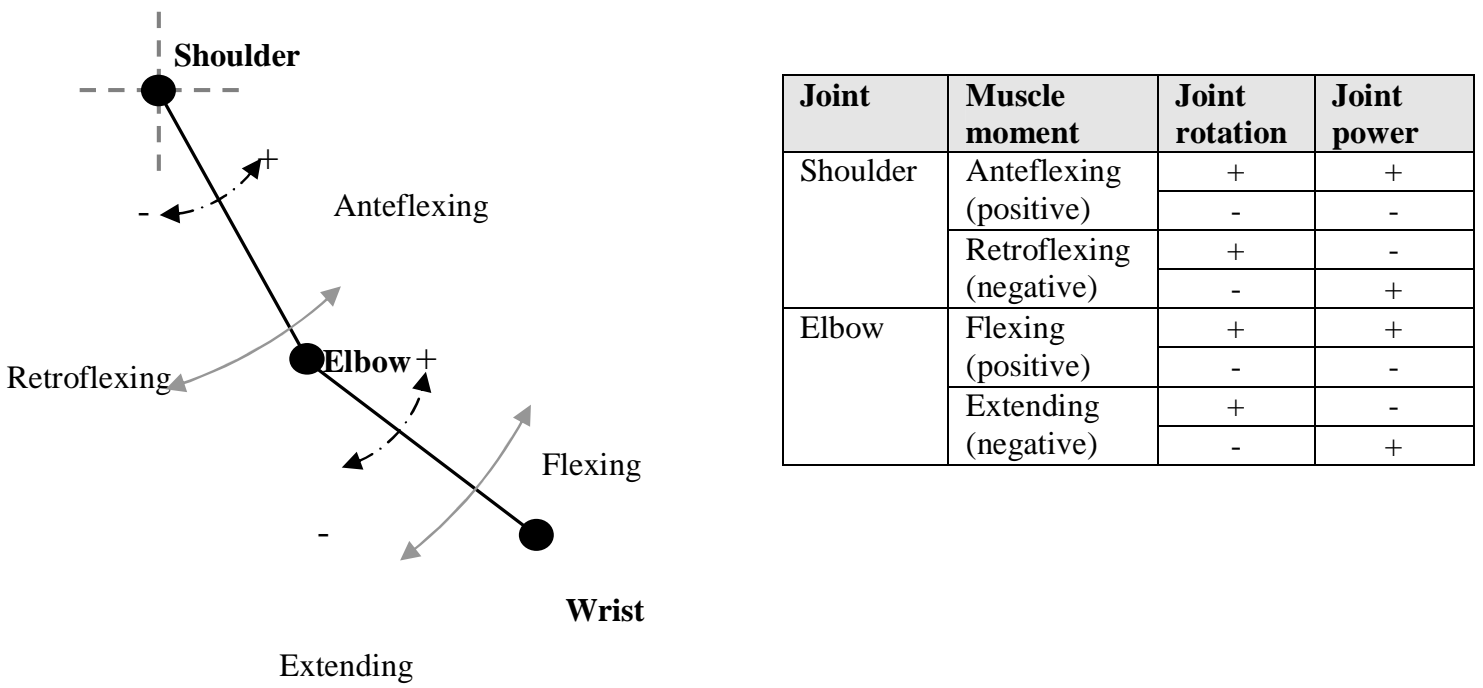

\section{Figure 8. Muscle moments and corresponding terminology, and sense of joint rotation and joint power.}

The muscle power, $P$, across a joint equals the product of muscle force, $F_{m}$, and muscle fibre velocity $v$ (shortening or stretching):

$\vec{P}=\vec{F} \bullet \vec{v}$

Alternately, the muscle power equals the product of the torque $T$ produced by a muscle about a joint and the associated the angular velocity $(\omega=d \theta / d t=\dot{\theta})$ of the limb segment [17]:

$\vec{P}=\vec{T} \bullet \vec{\omega}$

Elbow and shoulder power may be calculated directly from $\omega_{e}$ and $\omega_{s}$, respectively. The wheel velocity $\omega_{w}$ is not constant during the push phase but rather fluctuates to compensate for energy losses during the recovery phase (rolling resistance, aerodynamic drag). However, as the input variables are expressed as a function of $P P$ rather than as a function of time (Section 3), the power was normalised to the wheel's angular velocity $\omega_{w}$ which was assumed constant. Figure 9 shows the normalised muscle power versus push progress, $P P$. In the second half of the push phase, energy is taken out of the system by the eccentrically contracting shoulder retroflexors, whereas Richter's model [29] incorrectly predicts concentrically contracting shoulder anteflexors. Nevertheless, the graphical solution (Figure 
6) clearly shows that the direction of upper arm movement and shoulder torque are opposite, resulting in negative power.

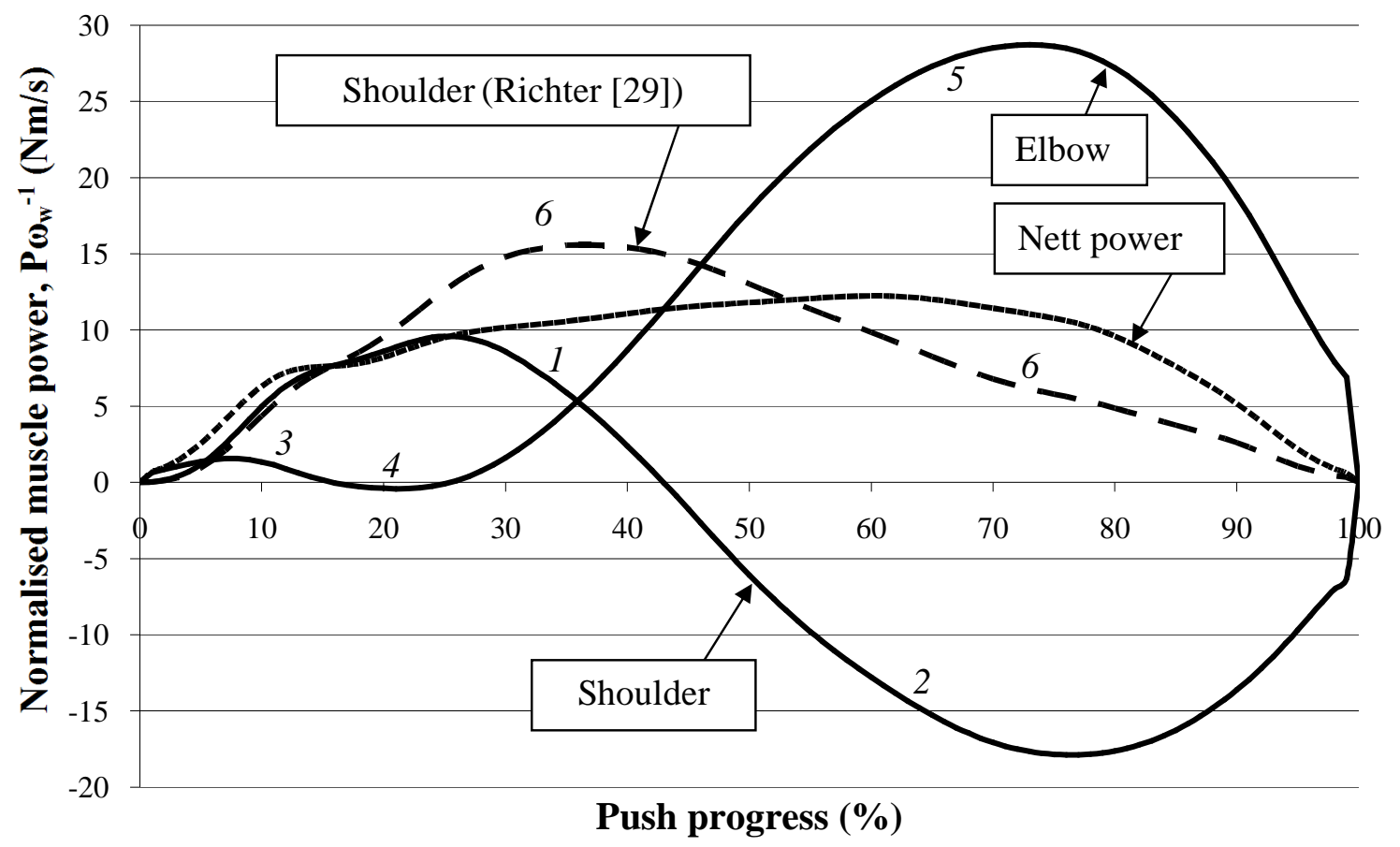

Figure 9. Normalised muscle power against the push progress,

showing: (1) concentric contraction of shoulder anteflexors, (2) eccentric contraction of shoulder retroflexors, $(3)$ concentric contraction of elbow flexors,

(4) negligible eccentric contraction of elbow extensor, (5) concentric contraction elbow extensor, (6) concentric contraction of shoulder anteflexors based on [29].

\section{Conclusion}

A fundamental theoretical model of shoulder and elbow torques was proposed to predict the shoulder and elbow torques required to maintain quasi-static equilibrium based on experimentally measured handrim forces. This model is particularly useful, as it is compatible with the available experimental data, and provides insight into the associated joint torques. This research provides a significant contribution to the existing theoretical models, with the following core outcomes:

- The proposed fundamental model agrees with the elbow torque predicted by previous work, but does not agree with the associated shoulder torque. Specifically, it appears that previously published work underestimates the peak positive shoulder torque and does not correctly predict the retroflexing shoulder muscle moment which occurs in the latter stages of the push cycle. This identified error was confirmed analytically, graphically and numerically.

- The model was applied to assess the effect of vertical seat position on joint torques and power. Increasing the seat height increases the peak positive joint torques while reducing the peak negative joint torques. A family of feasible joint curves were generated to demonstrate the applicability of the fundamental model for design optimisation. 
- The model was applied to obtain novel data on joint and net power as a function of push progress. This outcome provides a significant extension of the model utility by providing insight into athletic performance measures which are a function of power transmission.

\section{APPENDIX A}

By digitising the graphical information on handrim forces [29] a series of data points were obtained for tangential, $F_{t}$, and radial force, $F_{r}$, versus push progress, where $x$ is the push progress from $0(0 \%)$ to $100(100 \%)$. A Gaussian distribution (Prony series) was developed to provide the following representative equations:

$$
\begin{aligned}
& F_{t}(x)=a_{1} \exp \left\{-\left(\frac{x-b_{1}}{c_{1}}\right)^{2}\right\}+a_{2} \exp \left\{-\left(\frac{x-b_{2}}{c_{2}}\right)^{2}\right\}+a_{3} \exp \left\{-\left(\frac{x-b_{3}}{c_{3}}\right)^{2}\right\} \\
& +a_{4} \exp \left\{-\left(\frac{x-b_{4}}{c_{4}}\right)^{2}\right\}+a_{5} \exp \left\{-\left(\frac{x-b_{5}}{c_{5}}\right)^{2}\right\}+a_{6} \exp \left\{-\left(\frac{x-b_{6}}{c_{6}}\right)^{2}\right\}+a_{7} \exp \left\{-\left(\frac{x-b_{7}}{c_{7}}\right)^{2}\right\}
\end{aligned}
$$

Where:

$$
\begin{array}{llll}
a_{1}=36.09 & a_{3}=19.18 & a_{5}=0 & a_{7}=15.67 \\
b_{1}=65.94 & b_{3}=81.01 & b_{5}=38.54 & b_{7}=10.94 \\
c_{1}=15.89 & c_{3}=10.14 & c_{5}=0.04595 & c_{7}=6.417 \\
a_{2}=38.15 & a_{4}=20.88 & a_{6}=7.502 & \\
b_{2}=42.19 & b_{4}=22.37 & b_{6}=90.21 & \\
c_{2}=18.7 & c_{4}=11.95 & c_{6}=6.61 &
\end{array}
$$

$$
\begin{aligned}
& F_{r}(x)=a_{1} \exp \left\{-\left(\frac{x-b_{1}}{c_{1}}\right)^{2}\right\}+a_{2} \exp \left\{-\left(\frac{x-b_{2}}{c_{2}}\right)^{2}\right\}+a_{3} \exp \left\{-\left(\frac{x-b_{3}}{c_{3}}\right)^{2}\right\}+a_{4} \exp \left\{-\left(\frac{x-b_{4}}{c_{4}}\right)^{2}\right\} \\
& +a_{5} \exp \left\{-\left(\frac{x-b_{5}}{c_{5}}\right)^{2}\right\}+a_{6} \exp \left\{-\left(\frac{x-b_{6}}{c_{6}}\right)^{2}\right\}+a_{7} \exp \left\{-\left(\frac{x-b_{7}}{c_{7}}\right)^{2}\right\}+a_{8} \exp \left\{-\left(\frac{x-b_{8}}{c_{8}}\right)^{2}\right\}
\end{aligned}
$$

Where:

$$
\begin{array}{llll}
a_{1}=437.3 & a_{3}=-1137 & a_{5}=0 & a_{7}=899.4 \\
b_{1}=48.11 & b_{3}=59.61 & b_{5}=61.61 & b_{7}=66.45 \\
c_{1}=23.96 & c_{3}=31.57 & c_{5}=0.04234 & c_{7}=28.22
\end{array}
$$




$$
\begin{array}{llll}
a_{2}=24.04 & a_{4}=1.127 & a_{6}=115.1 & a_{8}=38.58 \\
b_{2}=42.1 & b_{4}=35.27 & b_{6}=25 & b_{8}=10.17 \\
c_{2}=14.41 & c_{4}=0.1983 & c_{6}=17.25 & c_{8}=7.778
\end{array}
$$

\section{Acknowledgements}

The authors gratefully acknowledge the invaluable contributions of the Australian Paralympic Rugby Team.

\section{Bibliography}

[1] Boninger M.L, Baldwin M., Cooper R.A., Koontz A., Chan L. (2000), Manual Wheelchair Pushrim Biomechanics and Hub Position. Archives of Physical Medicine and Rehabilitation, 81:608-13.

[2] Boninger M.L., Souza A.L., Cooper R.A., Fitzgerald S.G., Koontz A.M., Fay B.T., (2002), Propulsion Patterns and Pushrim Biomechanics In Manual Wheelchair Propulsion. Archives of Physical Medicine and Rehabilitation; 83:718-23.

[3] Boninger M.L., Koontz A.M., Sisto S.A., Dyson-Hudson T.A., Chang M., Price R., Cooper R.A. (2005) Pushrim Biomechanics and Injury Prevention In Spinal Cord Injury, Recommendations Based On CULP-SCI Investigations. JRRD, Vol: 42, Number 3, 9-20.

[4] Goosey-Tolfrey V.L., Fowler N.E., Campbell, I.G., Wnicki, S.D. (2001), A Kinetic Analysis Of Trained Wheelchair Racers During Two Speeds Of Propulsion. Medical Engineering and Physics 23 259-266.

[5] Richter W.M, Rodriguez R., Woods K.R., Axelson P.W. (2007), Stroke Pattern and Handrim Biomechanics for Level and Uphill Wheelchair Propulsion at Self-Selected Speeds. Archives of Physical Medicine and Rehabilitation; 88:81-7.

[6] Richter W.M, Rodriguez R., Woods K.R., Axelson P.W. (2007), Stroke Pattern and Handrim Biomechanics for Level and Uphill Wheelchair Propulsion at Self-Selected Speeds. Archives of Physical Medicine and Rehabilitation; 88:81-7.

[7] Richter W.M., Rodriguez R., Woods K.R., Karpinski A.P., Axelson P.W., Reduced Finger and Wrist Flexor Activity During Propulsion With a New Flexible Handrim. Archives of Physical Medicine and Rehabilitation 2006;87:1643-7.

[8] Veeger HEJ, van derWoude LHV, Rozendal RH. 1992a; Effect of handrim velocity on mechanical efficiency in wheelchair propulsion. Med Sci Sports Exerc 24 (1): 100-7

[9] Veeger HEJ, Hadj Yahmed M, van der Woude LHV, Charpentier P 1991;. Peak oxygen uptake and maximal power output of Olympic wheelchair-dependent athletes. Med Sci Sports Exerc 23(10):1201-9. 
[10] Dallmeijer AJ, van der Woude LHV, Veeger HEJ, Hollander AP. 1998; Effectiveness of force application in manual wheelchair propulsion in persons with spinal cord injuries. Am J Phys Med Rehab 77(3):213-21.

[11] Veeger HEJ, van der Woude LHV, Rozendal RH. 1992b; A computerized wheelchair ergometer. Scan J Rehabil Med 24: 17-23

[12] Van der Woude, L.H.V., Veeger, H.E.J., Dallmeijer, A.J., Janssen T.W.J., Rozendaal, L.A. (2001), Biomechanics And Physiology In Active Manual Wheelchair Propulsion. Medical Engineering and Physics 23 713-733.

[13] Burton M., Subic A., Mazur M., Leary M., (2010) Systematic Design Customization of Sport Wheelchairs using the Taguchi Method", Proceedings of 8th Conference of the International Sports Engineering Association (ISEA), Vienna, 12-16 July. [14] Asato, K., Cooper, R.A., Robertson, R.N., Ster, J.F (1993) SMART Wheels:

Development and Testing of a System for Measuring Manual Wheelchair Propulsion Dynamics, IEEE Transactions on Biomedical Engineering, VOL, 40, NO. 12.

[15] Cooper, R.A., (2009), SMARTWheel: From Concept to Clinical Practice, Prosthetics and Orthotics and International, 33(3): 198-209.

[16] Cooper R.A., Robertson R.N., VanSickle D.P., Boninger M.L., Shimada S.D (1997), Methods for determining three-dimensional wheelchair pushrim forces and moments: a technical note. J Rehabil Res Dev. 34(2):162-70.

[17] Winter DA, Robertson DG. (1978) Joint torque and energy patterns in normal gait. Biol Cybern. 31;29(3):137-42.

[18] Bastian, A.J., Martin, T.A., Keating, J.G., Thatch, W.T. (1996) Cerebellar ataxia: abnormal control of interaction torques across multiple joints, Journal of Neurophysiology 76 (1).

[19] Winter DA. (1983) Moments of force and mechanical power in jogging. J Biomech. 16(1):91-7.

[20] Brubaker, C.E. (1986) Wheelchair Prescription: An Analysis of Factors That Affect Mobility and Performance. Journal of Rehabilitation Research and Development Vol. 23 No. 4 Pages 19-26.

[21] van der Helm F.C. (1994) A finite element musculoskeletal model of the shoulder. J Biomech. 1994 May;27(5):551-69. 
[22] Guo L.Y., Su F.C., Wu H.W., An K.N. (2003) Mechanical energy and power flow of the upper extremity in manual wheelchair propulsion. Clin Biomech. 18(2):106-14.

mechanism, J Biomech. 27(5):551-69.

[23] Cooper, R.A., Boninger, M.L., Shimada, S.D., Lawrence, B.M. (1999) Glenohumeral joint kinematics and kinetics for three coordinate system representations during wheelchair propulsion. American journal of physical medicine rehabilitation Association of Academic Physiatrists 78(5): 435-446

[24] Koontz, A.M., Rory A.C., Boninger, M.L., Souza, A.L., Fay, B.T., (2002) Shoulder kinematics and kinetics during two speeds of wheelchair propulsion. Journal of Rehabilitation Research and Development 39 (6): 635-650.

[25] Dumas R., Aissaoui R., De Guise J.A., (2004) A 3D generic inverse dynamic method using wrench notation and quaternion algebra, Computer Methods in Biomechanics and Biomedical Engineering 7(3): 159-166.

[26] Desroches G., Aissaoui R. Bourbonnais, D. The Effect of Resultant Force at the Pushrim on Shoulder Kinetics During Manual Wheelchair Propulsion: A Simulation Study, IEEE Transactions on Biomedical Engineering, 55(4): 1423

[27] Sullivan S.R., Langrana N.A., Sisto S.A. (2005), Multibody Computational Biomechanical Model Of The Upper Body. ASME 2005 International Design Engineering Technical Conferences and Computers and Information in Engineering Conference September 24-28, Long Beach, California USA DETC2005-84809.

[28] Pennestri E, Stefanelli R, Valentini P P, Vita L. (2007) Virtual musculo-skeletal model for the biomechanical analysis of the upper limb [J]. Journal of Biomechanics, 40(6): 13501361.

[29] Richter W.M. (2001), The Effect Of Seat Position On Manual Wheelchair Propulsion Biomechanics: A Quasi-Static Model-Based Approach. Medical Engineering and Physics 23 707-712.

[30] Robertson, R.N., Boninger, M.L., Cooper, R.A., Shimada, S.D., (1996), Pushrim forces and joint kinetics during wheelchair propulsion. Archives of Physical Medicine and Rehabilitation, 77:856-64.

[31] Rodgers, M.M., Keyser.R.E., Gardner, E.R., Russell, P.J., Gorman, P.H., Influence of trunk flexion on biomechanics of wheelchair propulsion, Journal of Rehabilitation Research and Development 37(3), pp.283-295. 
[32] Boninger, M.L., Cooper, R. A., Baldwin, M.A., Shimada, S.D., Koontz, A. (1999), Wheelchair Pushrim Kinetics: Body Weight and Median Nerve Function. Archives of Physical Medicine and Rehabilitation, 80:910-5.

[33] Veeger HEJ, van der Woude LHV (1995) Force generation in manual wheelchair propulsion. In: Van Coppenolle H, Vanlandewijck Y, Simons J, et al., editors. Proceedings of the First European Conference on Adapted Physical Activity and Sports: a white paper on research and practice; 1994 Dec 18-20: Leuven. Leuven: Acco, pp. 89-94.

[34] Van der Linden ML, Valent L, Veeger HEJ, van der Woude LHV (1996) The effect of wheelchair handrim tube diameter on propulsion efficiency and force application. IEEE Trans Rehab Eng 4(3):123-32.

[35] Rodgers, M.M., Randall P.T., Keyser, E., Gardner, E.R., Russell, P.J., Gorman, P.H. (2000), Influence Of Trunk Flexion on Biomechanics Of Wheelchair Propulsion. Journal of Rehabilitation Research and Development Vol. 37 No. 3, May/June Pages 283-295.

[36] Vanlandewijck Y, Theisen D, Daly D (2001) Wheelchair propulsion biomechanics: implications for wheelchair sports. Sports Med 2001; 31 (5): 339-367.

[37] Desroches G., Aissaoui R., Bourbonnais D. (2008), The Effect of Resultant Force at the Pushrim on Shoulder Kinetics During Manual Wheelchair Propulsion: A Simulation Study. IEEE Transactions on biomedical engineering, vol. 55, no. 4.

[38] Boninger M.L.; Impink B.G.; Cooper R.A.; Koontz A.M. (2004), Relation Between Median And Ulnar Nerve Function and Wrist Kinematics During Wheelchair Propulsion. Archives of Physical Medicine and Rehabilitation 85:1141-5.

[39] Kotajarvi, B.R., Sabick, M.B., An, K-N. Zhao, K.D., Kaufman, K.R., Basford, J.R. (2004). The Effect of Seat Position on Wheelchair Propulsion Biomechanics. Journal of Rehabilitation Research \& Development, Volume 41, Number 3B, Pages 403-414

[40] Samuelsson K.A.M., Tropp H., Nylander E., Gerdle B., (2004), The Effect Of RearWheel Position On Seating Ergonomics And Mobility Efficiency In Wheelchair Users With Spinal Cord Injuries: A pilot study. Journal of Rehabilitation Research And Development. Vol:41;No:1;65-74.

[41] MSC ADAMS (2005), MSC.ADAMS Release Guide. MSC. Software Corporation, California, USA. 